\title{
The Effectiveness of Patient Safety Cultural Training with Mirror Method and Case Study on Nurse Understanding About Application of Patient Safety at Hospital Pekanbaru
}

\author{
Awaliyah Ulfah Ayudytha Ezdha', Silvia Nora Anggreini ${ }^{2}$, Dwi Elka Fitri ${ }^{3}$ \\ 1,2,3 STIKes Pekanbaru Medical Center, Pekanbaru Riau
}

\begin{abstract}
Quality development in hospitals has led to efforts to improve quality oriented towards patient safety. The purpose of this study was to compare what methods were most effective between lectures and case studies to improve nurses' understanding of the application of patient safety. The design of the research used is a mix method that is qualitative and quantitative. This research was carried out at Hospital in Pekanbaru with a sample of the study were all nurses who served at the hospital as many as 60 people. The results obtained from the study showed that the mean value of nurses 'understanding of patient safety habit after the lecture method training was 67.47 with a standard deviation of 8.320 while the mean value of nurses' understanding of the HABIT of patient safety after training in the case study method was 73.97 with a standard deviation of 6.835 . The independent $t$ test results obtained $p$ value $=0.002$. The results of this study are expected in addition to improving the understanding of nurses as well as the hospital can apply the most appropriate method so that the goals of the patient's safety goals are the quality of service can be achieved.
\end{abstract}

Keyword: Case study, Lecture, Patient Safety, Training.

Received 04 February 2019 | Revised 14 May 2019 | Accepted 26 January 2019

\section{Introduction}

Patient safety is a variable to measure and evaluate the quality of nursing services that affect health services. The patient safety program aims to reduce the number of adverse events that often occur in patients while being hospitalized so that it is very detrimental to both the patient and the hospital. Adverse event can be caused by a variety of factors including the high workload of nurses, inappropriate communication channels, inappropriate use of facilities and others [5].

In Indonesia, the incidence of adverse event especially near miss, is still rare, but on the other hand there is an increase in allegations of malpractice which is not necessarily in accordance

*Corresponding author at: STIKes Pekanbaru Medical. Pekanbaru.

E-mail address: Dhita_87@yahoo.com 
with the final proof. At Java with a population of 112 million people who suffered a loss of $4,544,711$ people that could be prevented as many as $2,847,288$ people, permanent disability as many as 337,000 people, deaths as many as 121,000 people with an economic burden of $495 \mathrm{M}$. Prevalence of adverse medical events patients in Central Java and DIY according to a study result is $1.8 \%-88.9 \%$ [12] .

To minimize the incidence of near miss, the Hospital Accreditation Committee (KARS) stated 6 patient safety goals as a condition to be applied in all hospitals accredited by KARS. This arrangement according to the WHO's nine life-saving Patient Safety Solutions (2007) which is also used by the Hospital Patient Safety Committee (KKPRS PERSI) and Joint Commission International (JCI). The six objectives are: identifying patients correctly, increasing effective communication, improve the safety of high-alert medication, ensuring the correct location of surgery, correct procedures, correct surgery for patients, controlling the risk of infection and reducing risk of falls.

Nursing services are provided with orientation to the goals of nursing services to be achieved. The achievement of the goal of nursing services in the hospital is influenced by the activities of nursing services provided to clients through the application of nursing care for the achievement of health care goals according to their duties, authorities and responsibilities and referring to professional standards (Law No. 36 of 2009 article 24). Quality and safe health services require the optimal role of every health worker, including nurses as the leading force in the service system.

The optimal role of nurses in the development of the quality of nursing services has evolved and led to the demand for adequate competence to support the patient safety. The Institute of Medicine (IOM) in 2000 proposed two roles of nurses in patient safety, namely maintaining safety through the transformation of a nursing environment that further supports patient safety and the role of nurses through the application of the latest nursing standards [6].

The socialization of programs and policies regarding patient safety in order to build the foundation for the required patient safety has been pursued nationally by KPP-RS through road shows in 12 major cities followed by workshops in several hospitals in Indonesia. However, a systemic approach is needed and an increase in the foundation of patient safety [8], [13], states that the foundation and pillars of patient care are safely composed of technology, processes and human resources. In connection with this matter, one of IOM's recommendations is to develop training programs in an interdisciplinary manner. The development of research in the form of interventions regarding patient safety should be directed to improve the ability of detection by nurses about signs of injury risk and can improve patient safety in an increasingly complex service environment [2].

Increased knowledge is the expected impact of training. Marquis and Huston (2006) stated that staff development programs through training and education are effective programs to increase nurse productivity. Adequate support in the form of professional training and knowledge 
development is one of the efforts to create a positive work environment for nurses to provide safe care (ICN, 2007).

Training is defined as an organized method to ensure that individuals have certain knowledge and skills and individuals gain good knowledge about obligations in their work. This knowledge can improve affective, motorbike and cognitive abilities so that an increase in productivity or good results will be obtained [9]. Research conducted by Hennessy, Hicks, Hilan and Kawonal (2006) of 524 nurses from 5 provinces in Indonesia, namely North Sulawesi, East Kalimantan, North Sumatra, West Java and DKI Jakarta found that all respondents significantly stated that need for training in tasks and work that nurses must do. This study also found that training needs were greater in groups of nurses working in the hospital. In the scope of patient safety, knowledge of HR (human resources) in health including nurses is something that is related to the commitment that is very necessary in an effort to build a habit of patient safety [1], [4]

There are several methods that can be applied in providing training that can be used in the development of human resources based on techniques and principles of learning are: On the job and off the job training. Off the job training consists of class lectures, case studies, simulations, laboratory practices, role playing and behavior modeling [2], [3]

Pekanbaru Medical Center Hospital is one of the class B private hospitals in Pekanbaru City with 86 nurses in 7 rooms including Inpatient room, Outpatient clinic ser[4]vices, ICU, Surgical Installation, Maternity Room and Emergency Room. The PMC Hospital has a Patient Safety Committee as a first step in constructive efforts in the framework of implementing patient safety policies as well as anticipating increasing customer expectations for quality services. PMC Hospital has a Patient motto to become a Center so that the PMC Hospital also puts forward patient safety in providing services. Based on the Survey conducted at the PMC Hospital the implementation of patient safety has been started since 2015 which began with the introduction of patient safety, the creation of a work system and the preparation of the KPRS team. An interview with the PMC Hospital KKP-RS team in March 2017 found that nursing staff at the PMC Hospital had not put reporting as one of the top priorities in supporting the implementation of seven steps towards patient safety that had been used as a policy. The absence of the same perception about filling in the reporting format for incidents, sorting incidents that are not so precise, and the feeling of fear of being blamed if reporting an incident was identified as an obstacle found by the KKP-RS Team in relation to the involvement of nurses in the implementation of patient safety programs. Nurses often have to be motivated to report incidents they find and often only verbal reporting processes also make it difficult to monitor incidents at the PMC Hospital. The no optimal values of awareness in building a patient safety habit that relates to the role of nurses through enhancing competence in supporting the implementation of patient safety programs that must be constantly reminded are also perceived conditions that must be addressed. Another method that can be used in giving patient safety material is the Case Study method. This is because patient safety is not only about theory but also equally important is the application in the field. The absence of research on the 
Comparison of the Effectiveness of training of Patient Safety Habit with the Lecture Method and Case Study on Nurse Understanding Regarding Patient Safety Implementation is an important reason why this research is important to do. Based on these considerations, researchers were interested in researching "Comparison of the Effectiveness training of Patient Safety habit by Lecture and Case Study method on the Understanding of Nurses Regarding the implementation of Patient Safety at the PMC Hospital".

\section{Research Methods}

The design of the research used is a mix method that is qualitative and quantitative. Quantitative methods are planned to be carried out in the first research to see the comparison of the application of the lecture method and the case study that is using quasi-experiments using the intervention group and the control group. Furthermore, for the second study, qualitative methods use a phenomenology approach to explore nurses' understanding of the application of patient safety and observation of the application in the field with FGD. Respondents were divided into 2 groups of 30 respondents in the lecture method group and 30 respondents in the case study method group.

\section{Research Result and Discussion}

Table 1. Differences in the value of nurses' understanding of patient safety habit in the lecture group and case study group after training

\begin{tabular}{lccccc}
\hline \multicolumn{1}{c}{ Variable } & \multicolumn{2}{c}{ Lecturer } & Case study & P value \\
\cline { 2 - 5 } & & Mean & SD & Mean & SD \\
& & & & & \\
\hline $\begin{array}{l}\text { Nurse's } \\
\begin{array}{l}\text { understanding of } \\
\text { the application of } \\
\text { patient safety }\end{array}\end{array}$ & 67,47 & 8,320 & 73,97 & & \\
\hline
\end{tabular}

Based on the $t$ dependent statistical test in table, the mean value of nurses' understanding of the patient safety habit after the lecture method training was 67.47 with a standard deviation of 8.320. The mean value of nurses' understanding of patient safety habit after training the case study method was 73.97 with a standard deviation of 6.835 . The independent $t$ test results obtained $\mathrm{p}$ value $=0.002$ smaller than the alpha value $(\mathrm{p}<0.05)$. This shows that there is a significant difference in the value of nurses' understanding of the patient safety habit with the lecture method and with the case study method, where the average value of nurses' understanding of patient safety habit after lecture method training was lower than the value of nurses' understanding of patient safety habit with the case study method. It can be concluded that training with the case study method is more influential in increasing the value of nurses' 
understanding of the application of patient safety than training with the lecture method. Motivational development, taking trainees' attention to what is learned, helping participants apply what they have learned, providing opportunities to practice new behaviors, and giving positive rewards to employee performance are the goals of the model developed in the form of training [11]. The employee training aims to improve the ability of employees to work through the improvement of management skills and functional technical programs concerned.

Training will also improve skills in their respective fields. The difference in group understanding of the lecture method and the case study group was concluded based on cognitive achievement seen from the comparison of the pre and post test scores. The direct influence of the learning process in training is evident but needs to be studied further the influence of training on other behavioral components. In accordance with the opinion of Suryabrata (2008) which states that to produce real behavioral changes, the involvement of complex processes is needed that are influenced by various internal and external factors of the individual. Spence (1956, in Morrison, 1991) states that learning theory through behavioral-oriented training was developed to carry out formal analysis of changes in behavior [12]

It means that the research results obtained should be accompanied by efforts to repeat the training program in the form of ongoing training to create adequate patterns in the memory of nurses regarding the implementation of patient safety in nursing services. Specifically given material is increasingly developed to have relevance to the jobs and responsibilities nurses' in providing safe care, and knowledge transfer can support nurses to learn quickly about the application of patient safety in nursing services. In addition, improvements in nurse performance standards that show the expected performance in implementing patient safety need to be developed and socialized and managed through advanced training programs in line with the KKPRS program.

By the results of the study, it is more effective to provide training with the case study method than the lecture method. According to researchers this can be caused because at the time of delivery of the material with the lecture method only one-way communication, while the case study method looks two-way communication. With two-way communication nurses who work in hospitals can conduct active discussions and directly apply to nursing services in the room. This of course further enhances their understanding. By thinking critically about the problems that exist, understanding the patient's safety will also deepen. This is based on the view expressed by Notoatmodjo (2007) which states that the environment influences the process of entry of knowledge into individuals in the environment. Mutual interaction or not will be responded to as knowledge by each individual from his environment. Gillies also states that learning in training is an active rather than passive phenomenon [3].

Achieving training goals should be useful in shaping the expected behavior and conditions that the organization wants to achieve appropriate performance [7]. It was also stated that training should be effective in accordance with the principles of learning that should be implemented in a continuous training program. The effectiveness of training also requires evaluation based on 
the development of staff capacity over time and the key to effective training programs not only consisting of participation but repetition, change of training and feedback is also important [7].

\section{Conclusion and Recommendations}

\subsection{Conclusion}

Based on the theoretical basis and supported by analysis and statistical test results, it can be concluded that there is a significant difference in the value of nurses' understanding of the patient safety habit with the lecture method and the case study method, with a $\mathrm{p}$ value $=0.002$ smaller than the alpha value $(\mathrm{p}<0.05)$. It can be concluded that training with the case study method is more influential in increasing the value of nurses' understanding of the application of patient safety than training with the lecture method.

\subsection{Recommendations}

In order to contribute ideas that are related to the improvement of science in the field of hospital administration, especially for the field of nursing, the following are suggested:

\subsubsection{Researcher}

It is better for researchers to develop learning tools about implementing patient safety goals and developing modules that are easier to understand. In addition, the provision of training sessions also needs to be observed so that respondents when receiving training can better understand.

\subsubsection{Respondents / Nurses}

More active in participating in training and evaluation so that nurses' understanding of patient safety goals is increased.

\subsubsection{Hospital}

Hospital should be able to develop appropriate training methods so that the goals to be achieved can be realized. In addition, consistent monitoring and evaluation is also needed so that ongoing training can also be carried out. This is very important in supporting and improving the quality of services in hospitals.

\subsubsection{Further Researchers}

As a baseline data comparison that can be used for further research in order to conduct research for other methods so that the hospital can find the right method to improve nurses' understanding that is adjusted to the conditions and background of the hospital.

\section{REFERENCES}

[1] Cahyono, J.B.S.B. (2008). Building a culture of patient safety in medical practice. Yogyakarta: Penerbit Kanisius

[2] Despins, L.A., Scott, C.J., \& Rouder, J.N. (2010). Detection of patient risk by nurses: a theoretical framework. Journal of Advanced Nursing, 66 (2), 465-474. http://www3.interscience.wiley.com/journal/123247860

[3] Gillies, D.A. (1994). Nursing management: a sistem approach. (3rd ed.) Phyladelphia: WB. Saunders Company

[4] Hennessy, D., Hiscks, C., Hilan, A., \& Kawonal, Y. (2006). The training and development needs of nurses in Indonesia: Paper 3 of 3. Human Resources for Health, 4

(10), 165-179. http://www.ncbi.nlm.nih.gov/pmc/articles/PMC1524804/pdf/1478-4491-4- 10.pdf 
[5] Huber, D.L. (2006). Leadership and nursing management. (3rd ed.). Philadelphia: Saunders Elsevier.

[6] Hughes, R.G (2008). Patient safety and quality: an evidence-based handbook for nurses. Rockville MD: Agency for Healthcare Research and Quality Publications.http://www.ahrq.gov/QUAL/nurseshdbk/

[7] Kohn, L.T., Corrigan, J.M., \& Donaldson, M.S. (2000). To err is human: building a safer health sistem. Washington DC: National Academies Press. Desember 20, 2009. http://www.nap.edu/openbook.php?isbn=0309068371.

[8] Lumenta, N.A (2008). State of the art patient safety. Presented at the Patient Safety and Clinical Risk Management Workshop at Harapan Kita Hospital on April 1-3, 2008. Jakarta: Not Published.

[9] Marquis, B.L. \& Huston, C.J. (2006). Leadership roles and management functions in nursing: therory and application. (5th Ed.). Philadelphia: Lippincott Williams \& Wilkins.

[10] Reed, S.K. (2000). Cognition: theory and applications. (5th ed.) USA: Wadsworth Thomson Learning.

[11] Rivai, V. \& Sagala, E.J. (2009). Human Resource Management for Companies: From Theory to Practice. 2nd edition. Jakarta: Rajawali Pers.

[12] Schoonhoven, L., Grobbee, D.E., Bousema, M.T., dan Buskens, E. (2005). Predicting pressure ulcers: cases missed using in a new clinical prediction rule. Journal of Advanced Nursing, 49 (1), 16-22.

[13] Yahya, A.A. (2006). The concept and program of patient safety. Presented at the VI National Hospital Quality Convention. Bandung. http://www.pdpersi.co.id 